\title{
Mortality pattern of the Alpine chamois: the influence of snow-meteorological factors
}

\author{
Tobias JONAS, ${ }^{1}$ Flavia GEIGER, ${ }^{1}$ Hannes JENNY ${ }^{2}$ \\ ${ }^{1}$ WSL, Swiss Federal Institute for Snow and Avalanche Research SLF, Flüelastrasse 11, CH-7260 Davos-Dorf, Switzerland \\ E-mail: jonas@slf.ch \\ ${ }^{2}$ Fish and Game Department of canton Grisons (AJF), CH-7001 Chur, Switzerland
}

\begin{abstract}
Especially for animals inhabiting alpine areas, winter environmental conditions can be limiting. Cold temperatures, hampered food availability and natural perils are just three of many potential threats that mountain ungulates face in winter. Understanding their sensitivity to climate variability is essential for game management. Here we focus on analyzing the influence of snow and weather conditions on the mortality pattern of Alpine chamois. Our mortality data are derived from a systematic assessment of 6500 chamois that died of natural causes over the course of 13 years. We use population- and habitat-specific data on snow, climate and avalanche danger to identify the key environmental factors that essentially determine the spatio-temporal variations in chamois mortality. Initially, we show that most fatalities occurred in winter, with a peak around March, when typically snow depths were highest. Death causes related to poor general conditions were the major component of seasonal variations. As for the interannual variations in mortality, snow depth and avalanche risk best explained the occurrence of winters with increased numbers of fatalities. Finally, analyzing differences in mortality rates between populations, we identified sun-exposed winter habitats with little snow accumulation as favourable for alpine chamois.
\end{abstract}

\section{INTRODUCTION}

Mountain and northern ungulates have to cope with severe ambient conditions during winter. The seasonal snow cover constrains locomotion (e.g. Parker and others, 1984; Dailey and Hobbs, 1989) and access to forage (Hovey and Harestad, 1992; Visscher and others, 2006), while low temperatures increase the energetic costs for thermoregulation. It does thus not astonish that previous studies were able to identify negative consequences of severe winters on the species' fitness (Cederlund and others, 1991; Crampe and others, 1997) and survival rates (e.g. Gaillard and others, 1993; Loison and Langvatn, 1998; Gonzalez and Crampe, 2001; see also Loison and others, 1999).

Mortality rates are an important aspect in population dynamics. Although we acknowledge density (e.g. Solberg and others, 2001) and cohort (Rose and others, 1998) effects on survival rates, in this study we focus on the specific and combined influence of extrinsic snow and weather factors on the mortality pattern of Alpine chamois (Rupicapra rupicapra).

The analysis is based on mortality data collected over the course of 13 years in canton Grisons, southeast Switzerland. The study area ranges over $7100 \mathrm{~km}^{2}$ from 260 to 4500 ma.s.l. Approximately 25000 chamois inhabit the area, grouped into 19 geographically separated populations.

Earlier studies have used a variety of winter severity indices, from simple mean snow depths to rather sophisticated measurands (e.g. Verme, 1968). Typically data from the nearest weather station have been used to determine relevant environmental drivers. This practice may, however, be inaccurate for alpine areas, as the distribution of temperatures and snow displays large gradients over small distances (Anderton and others, 2004). We therefore decided to employ geostatistical modelling methods to derive habitatspecific meteorological data.
The combination of the following circumstances enables novel insights in relating the pattern of chamois mortality to extrinsic snow and weather factors: (1) Our study comprises multi-population and multi-year mortality data; (2) we account for population- and habitat-specific snow and weather data; and (3) an avalanche risk index is included in the set of explanatory factors.

\section{DATA AND METHODS}

\subsection{Meteorological data}

Geostatistical modelling allows data to be distributed from a set of weather stations to a grid. Detrended kriging and inverse distance weighting are two methods widely used to interpolate standard parameters from meteorological networks (see Gyalistras, 2003; Haberlandt, 2007). While airtemperature distributions often feature an approximately constant lapse rate, this is certainly not the case for snowdepth gradients. Therefore, a special detrending algorithm was developed to cope with the typical nature of vertical snow distributions (Foppa and others, 2007).

Geostatistical detrended interpolation methods can only produce accurate results if the spatial density of input data is high enough to reflect (1) elevation gradients and (2) regional trends of the respective parameter. We thus allocated data from four monitoring networks, from 150 stations (Fig. 1), for six meteorological parameters and for 13 years: Two snowmonitoring networks run by the Swiss Federal Institute for Snow and Avalanche Research (SLF) supplied data on snow depth (HS) and daily new snow sum (HN). Additionally, the Swiss Federal Office of Meteorology and Climatology (MeteoSwiss) provided data on air temperature (TA), precipitation (PREC), wind speed (WS) and relative sunshine duration (SUN) from two further measuring networks. Most of the 150 stations featured data for only two or three out of 
Table 1. Availability of snow and weather data: number of stations that provided a 13 year data record for a specific meteorological parameter. Records were not considered if more than 2 out of 13 years of data were missing/faulty

\begin{tabular}{lrrrrrc}
\hline Network & HS & HN & TA & PREC & WS & SUN \\
\hline $\mathrm{VG}^{1}$ & 28 & 27 & - & - & - & - \\
$\mathrm{MS}^{1}$ & 11 & 9 & - & - & - & - \\
$\mathrm{KKS}^{2}$ & 10 & 13 & 29 & 5 & 25 & 24 \\
NIME $^{2}$ & 9 & 14 & - & 82 & - & - \\
Total & 58 & 63 & 29 & 87 & 25 & 24 \\
\hline
\end{tabular}

HS: Snow depth; HN: new snow sum; TA: air temperature; PREC: precipitation sum; WS: wind speed; SUN: relative sunshine duration.

${ }^{1}$ Measuring network run by SLF.

${ }^{2}$ Measuring network run by MeteoSwiss.

the six parameters considered here. A data record (i.e. a 13 year series of daily data for one parameter at one station) was only considered if less than 2 years of data were missing/faulty. To ensure homogeneous data quality, all input data were thoroughly checked for plausibility, cropped where necessary and corrected where possible. Altogether, 286 data records were available for this study (Table 1 ).

The snow and meteorological data were interpolated to grid using WinMet (http://www.hydrologie.unibe.ch/ PREVAH; Viviroli and others, 2007), where for each parameter the methodology was optimized specifically. This procedure resulted in six grids per day (i.e. $13 \times 365 \times 6=$ 28470 grids), featuring the spatial distribution of $\mathrm{HS}, \mathrm{HN}$, TA, PREC, WS and SUN with $500 \mathrm{~m}$ gridcell spacing. Note that geostatistical detrended interpolation mainly reflects elevational gradients and spatial pattern resolved by the station network. But the method does not correct for aspect and slope.

At this stage, we added an avalanche risk index as a seventh potential environmental driver. The spatial distribution of this parameter required a different approach. The daily Swiss avalanche danger bulletin (http://www.slf.ch) provided the basis for calculating a site-specific avalanche risk index. Based on topographic adjustment procedures (see Leuthold and others, 1997), the regional danger index was modified by means of site-specific weighting factors. These weighting factors quantitatively took into account how well aspect, slope and altitude matched the dangerous areas as specified in the bulletin.

\subsection{Mortality data}

For management purposes, the Fish and Game Department of canton Grisons (AJF) has systematically collected data on chamois mortality since 1992. All carcasses found, whether by the professional game wardens on patrol or by hunters or hikers, are to be reported to the AJF. The carcasses (including incomplete leftovers) are evaluated by trained staff according to a fixed protocol. Besides place and date of discovery, for each carcass found sex, age, cause of death and date of death are determined or estimated wherever possible.

Determination of the date of death was especially relevant for this study. Sometimes carcasses were only found after months, especially after melt-out and again in later summer at the beginning of periods of high activity of hikers/

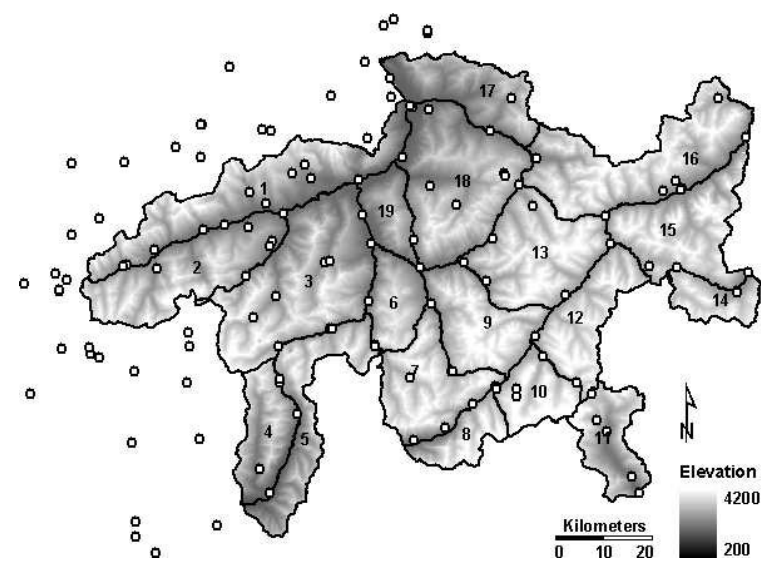

Fig. 1. Canton Grisons, Switzerland: location of snow and weather stations (open circles) and territories of the 19 chamois populations (bordered by black lines).

hunters (preparing for the autumnal hunt). Roughly $45 \%$ of the carcasses were older then 2 weeks. Based on finding date and carcass age (in a set of categories), we recalculated the date of death, albeit with decreasing accuracy for older carcasses. For very old carcasses the assessment distinguished between 'died in summer' and 'died last winter', thus allowing each fatality to be attributed to at least a specific summer/winter season.

Causes of death were recorded in 34 categories, which we aggregated to the six main categories listed in Table 2. In the following we only consider natural mortality and thus disregard the categories 'Shot' and 'Road kills'. This procedure yielded a total of 6500 data records of chamois that died of natural causes over the course of the study period.

The chamois inhabited 19 administrative units, which have been chosen to reflect self-contained populations (Fig. 1). The boundaries between these units typically comprise major rivers, highways and major roads, while part of the outer rim was defined by rather arbitrary borders. These boundaries may not be completely insuperable for chamois, but they are useful for considering populations as being geographically separated, at least to a certain degree.

To compare mortality rates between populations (see section 3.3), the mortality counts had to be normalized by the respective population sizes (hereafter referred to as relative winter mortality). There were only rough data available on annual variations in population sizes. Instead we used one accurate population-size estimate per population for the

Table 2. Incidence of different causes of death

Cause of death Number of cases

Poor general conditions, diseases ${ }^{1}$

Natural accidents ${ }^{1,2}$

Predation $^{1}$

3172

Road kills

1757

Road kills

Unknown causes ${ }^{1}$

Shot $^{3}$

1494

484

${ }^{1}$ Only these categories were counted as natural mortality.

${ }^{2}$ This category contains the sub-category 'avalanche accidents' (see Fig. 4).

${ }^{3}$ Outside the regular hunt. 


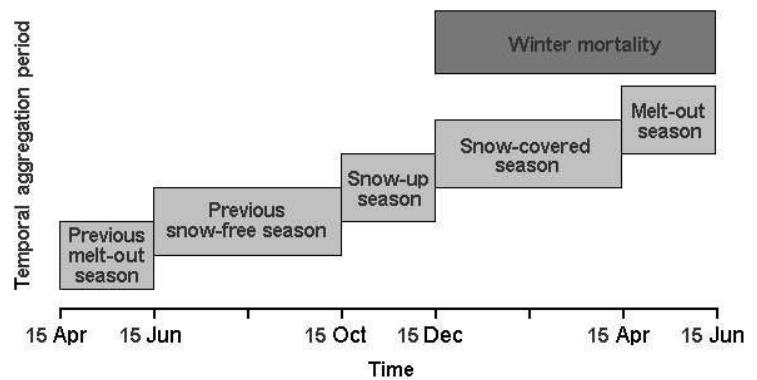

Fig. 2. Scheme for temporal aggregation of data. The number of mortalities with a 15 December-15 June date of death is referred to as winter mortality. Associated snow and meteorological data are temporally aggregated in concurrent or preceding periods: melt-out season (15 April-14 June), snow-free season (15 June-14 October), snow-up season (15 October-14 December) and snow-covered season (15 December-14 April).

whole period and accounted for interannual effects by a random factor in our mixed-effects model (see section 2.4). Population-size estimates were reconstructed based on hunting and carcass data over 13 years. Given the hunting level vs natural mortality rates, and the fact that all hunted chamois were analyzed for age and sex, these reconstructions were presumably quite accurate.

Note that the populations are managed, whereas hunters may take down about 4000 chamois annually in autumn. The sex-, age- and population-specific hunting quotas were adapted each year according to actual density and age structures. Thus, population structures were rather stabilized by management, and density effects should not greatly confound our analysis of aggregated winter mortality data. Since we see no reason to suppose a different average presence/activity of game wardens and hunters between years, we assume that the probability of detecting a carcass is approximately constant on a year-to-year basis. However, the seasonal statistics may be biased in this respect. Large predators (wolf/lynx/bear) were largely absent in the study area, with only occasional occurrences of wolf or lynx. Given that predation was only an insignificant contribution to the overall mortality (Table 2), variability in predator abundance should not confound our results.

\subsection{Data aggregation}

For a first overview of the mortality data, the records were summarized in monthly statistics (see section 3.1). The temporal classification was based on the date of death, i.e. not on the date when the carcass was found. In this context, we could only include mortality records that allowed the date of death to be determined within an accuracy of at least a few weeks ( $83 \%$ of data).

For the further analysis, we concentrated on the variability of winter mortality, which enabled season-specific effects of environmental drivers to be assessed. We did not consider environmental drivers with a time lag of $>1$ year, since the hunting regime (see section 2.2) was expected to equalize long-term effects. The analysis required merging

Table 3. Variables used in mortality statistics: units, range, methods used in seasonal spatio-temporal aggregation, and transformations

\begin{tabular}{|c|c|c|c|c|c|c|c|c|c|}
\hline & HS & $\mathrm{HN}$ & TA & PREC & WS & SUN & $\mathrm{ARI}^{1}$ & $\begin{array}{l}\text { Winter } \\
\text { mortality }\end{array}$ & $\begin{array}{c}\text { Relative winter } \\
\text { mortality }\end{array}$ \\
\hline Unit & $\mathrm{cm}$ & $\mathrm{cm}$ & ${ }^{\circ} \mathrm{C}$ & $\mathrm{mm}$ & $\mathrm{ms}^{-1}$ & $\%$ & - & - & $\%$ \\
\hline Lower limit & 0 & 0 & - & 0 & 0 & 0 & 0 & 0 & 0 \\
\hline Upper limit & - & - & - & - & - & 100 & 7.6 & - & 100 \\
\hline Mean value ${ }^{2}$ & 64 & 312 & -1.2 & - & 4.8 & 50 & 3.1 & 18 & 1.4 \\
\hline Melt-out season & $\begin{array}{c}\text { mean } \\
\text { days25 }\end{array}$ & $\begin{array}{c}\text { sum } \\
\text { days5 } \\
\text { days25 }\end{array}$ & $\begin{array}{c}\text { mean } \\
\text { days-10 }\end{array}$ & sum & $\begin{array}{l}\text { mean } \\
\text { days5 }\end{array}$ & mean & $\begin{array}{c}\text { mean } \\
\text { days4.5 }\end{array}$ & sum $^{*}$ & $\operatorname{sum}^{*}$ \\
\hline Snow-covered season & $\begin{array}{c}\text { mean } \\
\text { days25 }\end{array}$ & $\begin{array}{c}\text { sum } \\
\text { days5 } \\
\text { days25 }\end{array}$ & $\begin{array}{c}\text { mean } \\
\text { days-10 }\end{array}$ & - & $\begin{array}{l}\text { mean } \\
\text { days5 }\end{array}$ & mean & $\begin{array}{c}\text { mean } \\
\text { days4.5 }\end{array}$ & & \\
\hline Snow-up season & $\begin{array}{c}\text { mean } \\
\text { days25 }\end{array}$ & $\begin{array}{c}\text { sum } \\
\text { days5 } \\
\text { days25 }\end{array}$ & $\begin{array}{c}\text { mean } \\
\text { days-10 }\end{array}$ & sum & $\begin{array}{l}\text { mean } \\
\text { days5 }\end{array}$ & mean & $\begin{array}{c}\text { mean } \\
\text { days4.5 }\end{array}$ & - & - \\
\hline Previous snow-free season & - & - & $\begin{array}{c}\text { mean } \\
\text { days-10 }\end{array}$ & sum & $\begin{array}{l}\text { mean } \\
\text { days5 }\end{array}$ & mean & $\begin{array}{c}\text { mean } \\
\text { days4.5 }\end{array}$ & - & - \\
\hline Previous melt-out season & days 25 & $\begin{array}{c}\text { sum } \\
\text { days5 } \\
\text { days25 }\end{array}$ & $\begin{array}{c}\text { mean } \\
\text { days-10 }\end{array}$ & sum & $\begin{array}{l}\text { mean } \\
\text { days5 }\end{array}$ & mean & $\begin{array}{c}\text { mean } \\
\text { days4.5 }\end{array}$ & - & - \\
\hline
\end{tabular}

Note: The following acronyms for aggregation methods are used in the data analysis: mean: mean value; sum: seasonal sum; days $5^{\dagger}$ : number of days with $\mathrm{HN}>5 \mathrm{~cm}$, WS $>5 \mathrm{~m} \mathrm{~s}^{-1}$; days $4.5^{\dagger}$ : number of days with ARI $>4.5$; days $-10^{\dagger}$ : number of days with TA $<-10^{\circ} \mathrm{C}$; days $25^{\dagger}$ : number of days with $\mathrm{HS} / \mathrm{HN}>25 \mathrm{~cm}$.

${ }^{1} \mathrm{ARI}$ is a quasi-continuous variable with 66 possible levels; ARI $>4.5$ can be interpreted as high risk.

${ }^{2}$ Averaged/summed over snow-covered and melt-out season.

${ }^{*}$ Variable $x$ was transformed using $\log (x)$. ${ }^{\dagger}$ Variable $x$ was transformed using $\operatorname{sqrt}(x)$. "Variable $x$ was transformed using asin(sqrt( $\left.x\right)$ ). 


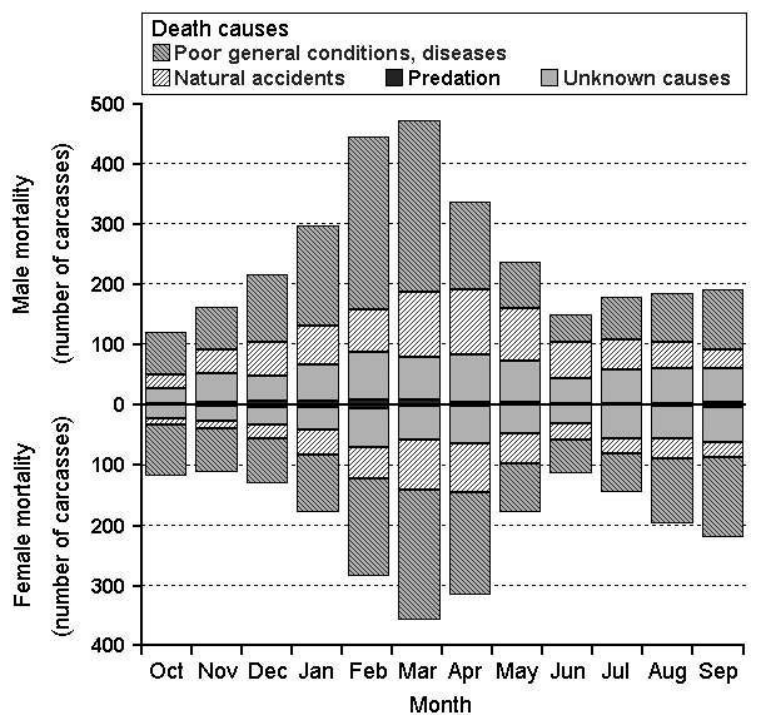

Fig. 3. Natural mortality of chamois by month, sex and cause of death. Carcasses that could not be attributed to a sex were counted as 0.5 male and 0.5 female. The temporal classification is based on date of death.

the mortality data (single case records) with the snow and weather data (daily meteorological grids). For this purpose, we first pooled the mortality records in $19 \times 13$ data fields containing per population per winter season the cumulated number of mortalities with a date of death between 15 December and 15 June. Then each of the $19 \times 13$ data fields was complemented with specific snow and weather data: per winter season and meteorological parameter we produced a set of seasonal grids by aggregating the daily grids over five concurrent or preceding periods (Fig. 2).

For the spatial aggregation of these meteorological grids, the AJF provided data on population-specific seasonal habitats (known traditional winter and summer habitats). These allowed the snow and weather data to be evaluated for each population specifically within their expected seasonal residence areas. We used the summer habitats as aggregation domain for melt-out and snow-free seasons, and the winter habitats as aggregation domain for snow-up and snow-covered seasons respectively.

As aggregation methods we used averaging, summing and conditional counts (Table 3). Ultimately, the procedures described above resulted in $19 \times 13$ data fields containing per population and winter season the number of mortalities, and 58 associated population, habitat and season-specific environmental indices (see respective entries in Table 3 ).

Finally, geomorphological habitat characteristics were included in the dataset as additional explanatory variables for analyzing the variability of mortality between populations (see section 3.3). We therefore evaluated elevation, slope and aspect of the population-specific seasonal habitats using a digital elevation grid of $100 \mathrm{~m}$ horizontal resolution.

\subsection{Statistical methods}

As a matter of principle, the mortality of chamois displayed variability between years and between populations. The changes in mortality counts between years may reflect the interannual variability of environmental factors. On the other hand, steady differences of relative mortality rates between populations may, among other factors, relate to

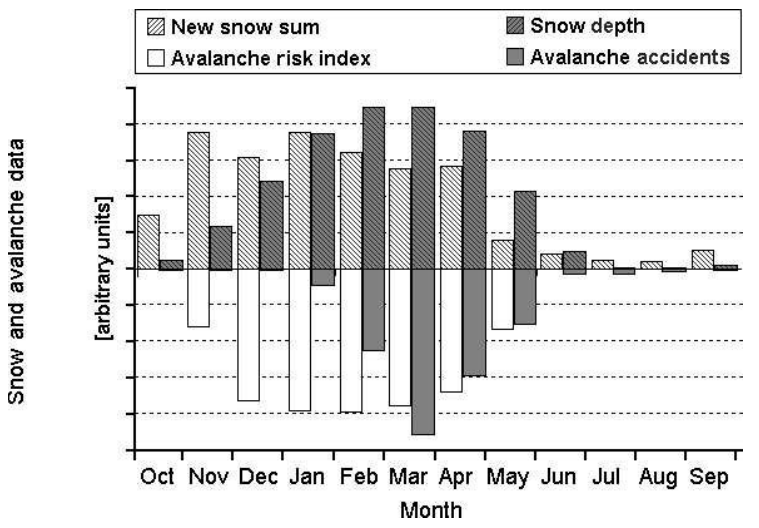

Fig. 4. Snow depth, new snow sum, avalanche risk index, and fatalities due to avalanches (see Table 2) in terms of months. All data scaled to arbitrary units.

persistent regional climate gradients. That is why we analyzed between-years effects and between-populations effects of snow and weather separately.

We used linear mixed-effects models with population as random factor in order to investigate between-years effects. With this method the influence of intrinsic factors on mortality was accounted for by the random effect (population). The extrinsic fixed effects (snow and weather) were then tested against the residuals. Between-population effects were analyzed the same way, except that in this case we used year as the random factor. Response variables and explanatory variables were transformed where appropriate using standard filters (Table 3 ) to meet the assumption of normality and homoscedasticity.

The selection of a best-fit model followed stepwise backward-forward selection methods in S-PLUS (Insightful Corporation, Seattle, WA, USA) based on Akaike's information criterion (AIC; Akaike, 1981). However, where problematic we suppressed the presence of strongly correlated explanatory variables in the best-fit models by manually removing one of two correlated variables and rerunning the model selection procedure.

\section{RESULTS}

\subsection{Mortality and season}

Averaged with respect to year and populations, the mortality data showed a clear seasonal pattern (Fig. 3). Mortality peaked around February to March, when typically snow depths were highest (Fig. 4). The intra-annual variability was dominated by fatalities related to poor general conditions and diseases. This category represented $49 \%$ of all cases and $63 \%$ of the cases with known cause of death respectively. Accident-related deaths (fall, avalanches) tended to occur towards the end of the winter in March to May. Ten per cent of all fatalities were attributed to avalanches. Predation rates were marginal.

Note that the data shown in Figures 3 and 4 only represent $83 \%$ of all records, since an approximate date of death could not be determined for $17 \%$ of the carcasses. As most of the undatable carcasses were found around melt-out in May, many of these cases may represent fatalities of the snow-up period. This period might thus be slightly underrepresented in the mortality statistics (Fig. 3). Note also that the mortality counts in August and September are presumably biased due 
Table 4. Linear mixed-effects model for the interannual variability of the mortality of Alpine chamois. $71 \%$ of the variance is accounted for by random and fixed effects together, and $36 \%$ by the fixed effects alone

\begin{tabular}{lc}
\hline Response & Winter mortality \\
\hline $\begin{array}{l}\text { Random effect } \\
\text { Fixed effect } 1\end{array}$ & $\begin{array}{c}\text { Population identifier } \\
\text { HS, snow-covered season, mean }\end{array}$ \\
Fixed effect 2 & (Std coeff.: $0.37 ; p<0.000 ;$ SE $=1.93)$ \\
& ARI, snow-up season, days4.5 \\
$R_{\text {fix }+ \text { random }}{ }^{1}$ & (Std coeff: $0.16 ; p<0.001 ; \mathrm{SE}=0.29)$ \\
$R_{\text {fix }}{ }^{1}$ & 0.71 \\
\end{tabular}

${ }^{1}$ Calculated according to Xu (2003), $R_{\text {fix }}^{2}$ random represents the variance of the response variable explained by fixed and random effects, while $R_{\text {fix }}^{2}$ represents the variance explained by fixed effects alone.

to the autumnal hunt. The activity of hunters is likely to increase the carcass detection probability and might even induce additional (natural) fatalities due to stress. However, elevated mortality counts in August and September also reflect occurrences of Mycoplasma conjunctivae, which cause additional fatalities primarily during these 2 months (Giacometti and others, 2002).

\subsection{Winter mortality and weather}

Between-years effects consider the influence of environmental drivers on the interannual variability of mortality, i.e. we determine which snow and weather conditions entail years with increased numbers of fatalities. In the following, we concentrate on the variability of winter mortality, which enables timing issues between environmental drivers and mortality as response to be assessed.

The variance analysis revealed that winter mortality counts of chamois were predominantly associated with mean snow depths during the snow-covered period (Table 4), as also reported in previous studies (e.g. Gonzalez and Crampe, 2001). The avalanche risk index during the snow-up season was identified as a secondary predictor for mortality. It is remarkable that neither snow depth during melt-out nor any measure of the winter length appeared in the best-fit model. Hence, spring weather conditions seem less critical. Moreover, we did not find any association between winter mortality and our explanatory variables from the preceding snow-free season.

Alternative models for the variability of winter mortality between years were similar and also listed snow depth and avalanche risk index as the only two explanatory variables, but aggregated over crosswise exchanged periods and/or with different methods. The second-best model (relative increase of $\mathrm{AIC}$ by $2 \%$ ) consisted of fixed effect 1 : HS, snowup season; fixed effect 2: ARI, snow-covered season. Both factors, aggregated over the same periods, were considerably correlated and to a certain degree interchangeable in the models.

\subsection{Winter mortality and habitat}

Analyzing between-populations effects represents the question whether variations in the mortality rates of different populations can be linked to differences in the climatic suitability of their respective habitats. The analysis
Table 5. Linear mixed-effects model for the variability of the relative mortality rate of Alpine chamois between populations. $46 \%$ of the variance is accounted for by random and fixed effects together, and $27 \%$ by fixed effects alone

Response Relative winter mortality
Random effect

Fixed effect 1

Fixed effect 2

Fixed effect 3

$R_{\text {fix random }}^{2}$

$R_{\text {fix }}^{2}$

Southerly aspect means lower mortality rate.
Year identifier

SUN, snow-up season, mean (Std coeff.: $-0.62 ; p<0.000 ; \mathrm{SE}=0.54$

HS, snow-covered season, mean (std coeff.: $0.37 ; p<0.000 ;$ SE $=1.93$ ) Aspect of winter habitat ${ }^{1}$ (std coeff.: 0.06; $p=0.003 ; \mathrm{SE}=0.07$ )

0.46

0.27 is performed on relative winter mortality, i.e. the absolute number of carcasses per population and year divided by the respective population size. This normalization was necessary to compare mortality between populations with different sizes.

The best-fit model (Table 5) involved a strong association between autumn weather and relative winter mortality: habitats that often see sunny weather conditions during snow-up are inhabited by populations with consistently lower mortality rates. The same applies to habitats with below-average snow depths in winter (see Wiersema, 1989). Neither habitat slope nor altitude related to mortality. On the other hand, south-facing habitats were inhabited by populations with significantly lower mortality rates, although this effect was minor. These findings exactly match the habitat preferences of chamois in winter (e.g. Michallet and others, 1999). The only alternative model with similar performance (relative increase of AIC by $1.5 \%$ ) was almost identical but listed accumulated new snow instead of mean snow depth, both aggregated over the snow-covered period.

\section{DISCUSSION}

The mortality pattern displayed a clear link to the variability of snow and weather factors. To assess these results, it is important to consider the spatial and temporal scales involved in our analysis (e.g. Johnson and others, 2002; Boyce and others, 2003). As a consequence of the chosen approach, the level of spatio-temporal aggregation of mortality, snow and weather data is considerable. Explanatory meteorological variables have been aggregated over periods of 2-4 months and within habitat areas of 0.25 to several $\mathrm{km}^{2}$. This, in particular, dilutes the effect of extreme weather events, which act on much shorter timescales (days). But episodic events like the occurrence of rain-on-snow or heavy snowstorms may significantly contribute to overall winter mortality (Putkonen and Roe, 2003). To account for extreme weather nevertheless, we alternatively aggregated data using conditional counts (see Table 3 (e.g. days with $\mathrm{HN}>25 \mathrm{~cm})$ ). However, these variables were not included in our best-fit models. In this context, it is important to note that using carcass data is not compatible with an analysis of high temporal resolution. A considerable percentage of the carcasses did not allow accurate determination of the date 
of death. Thus, also the response variable (mortality) featured a temporal blur of a few months, which was why an aggregation to seasonal counts was most appropriate. As for the spatial aggregation, we had no consistent information about the temporary locations of the individual populations. Thus, with respect to winter mortality, the smallest meaningful spatial scale was defined by the sizes of the traditional winter habitats (i.e. areas that encompass typically used winter habitat). Given the above considerations, our analysis can only deal with those effects of environmental factors on mortality that act on broader spatial and temporal scales.

As a further limitation, our analysis is potentially confounded by possible deviations from a constant carcass detection probability in space and/or time. The detection probability is certainly related to the activity of hunters or hikers and thus presumably not constant over the course of the year. This would be unproblematic if (1) all carcasses were found and (2) the date of death could be accurately determined for all carcasses. Since this is not entirely the case, the mortality data may not represent all periods of the year in equal measure. Therefore, our monthly statistics on mortality counts are rather meant in a descriptive way and cannot reflect the exact intra-annual pattern with monthly resolution. As for the interannual analysis of the mortality pattern (see section 3.2), we rate the assumption of constant carcass detection probability between years as fairly reasonable. Probably less accurate is to assume a constant detection probability between populations. Confounded results may arise if the suitability of winter habitats is correlated with factors influencing the probability that a carcass is found (e.g. steep terrain). Therefore (and for other reasons) it is not astonishing that the remaining unexplained variance of the model in Table 5 (variation in relative winter mortality between populations) is higher than that of the model in Table 4 (variation in winter mortality between years).

Despite our critical discussion above, our results certainly add to the overall understanding of climate effects on chamois mortality. The seasonal pattern of fatalities shows that the highest mortality occurs in midwinter simultaneously to the course of the snow accumulation. This suggests that primarily winter weather should have a significant effect on our respective mortality figures. Previous studies have, indeed, identified a link between severe winters and chamois survival (Gonzalez and Crampe, 2001). Winter severity has, amongst others, been described using maximum/mean snow depths, cumulative snowfall or according to occurrences of extreme weather events. From a seasonal perspective, one of the simplest of all measures, the mean snow depth during the snow-covered season, gained the best correlation to winter mortality counts, although a whole range of respective variables were tested (see Table 3): winter length (HS, days25), the occurrence of severe snowstorms ( $\mathrm{HN}$, days25), and considerable avalanche danger (ARI, days4.5) to name a few. The mean snow depth seems to be a good integrator of a range of possible effects of winter environmental conditions on mortality, presumably especially if it comes to a large dataset (multi-year/multi-population). If, for example, increased numbers of fatalities are caused by severe snowstorms in one winter and by intensive avalanche activity in another winter, these effects will be linked to higher than average snow depths in both years.

Certainly, special environmental conditions in spring may affect survival (Loison and Langvatn, 1998). However, snow and meteorological factors from the melt-out season were not included in our best-fit models. One reason for this may be the fact that fatalities during the melt-out season only constitute a lesser contribution to the overall winter mortality ( $25 \%$; see Fig. 3). Secondly, special environmental conditions in spring causing severely increased mortality counts may occur too sporadically in our project area to have a significant effect on the overall mortality pattern.

Using some caution, our results also allow identifying environmental factors (weather and geomorphology) that relate to traditional winter habitats of populations with mortality figures below average. Again, it seems that the average snow depth within a habitat describes a factor of its suitability. Carcass detection probability issues should not confound this result, as we would rather expect higher detection probabilities in habitats with lesser snow accumulations, which in fact feature the lowest mortality counts. The same argument applies to the link between relative sunshine duration and mortality, as sunny habitats should rather attract human activity (resulting in higher detection probabilities). We can only speculate about specific effects that cause habitats with increased exposure to sun during the snow-up season to accommodate populations with lower mortality counts: maybe less accumulation of snow due to melting effects and/or food availability issues. However, obviously actual (sunshine duration) and potential (aspect) sun exposure seems to constitute an index that reflects another factor of habitat suitability.

\section{CONCLUSIONS}

This study addresses the influence of extrinsic snow and weather factors on the mortality pattern of Alpine chamois. We analyzed 13 years of mortality data from 19 geographically separated chamois populations that inhabit southeast Switzerland. As explanatory variables, habitat-specific meteorological data were derived from a large set of weather station records using geostatistical interpolation methods.

Our results primarily reflect those effects of environmental factors on mortality that act on broader spatial and temporal scales. The mortality data displayed a clear seasonal pattern, with a peak increase in midwinter around February to March. This is the time of the year when snow depths are usually maximal. We show that the snow-rich winter entailed increased numbers of chamois fatalities. Of a whole range of snow meteorological variables, the mean snow depth and the number of days exceeding a critical level of avalanche danger best explained the interannual variability of chamois mortality. Comparing habitat characteristics with mortality variations between populations, the most suitable habitats were identified as sunny, southerly-exposed and with below-average snow depths.

\section{ACKNOWLEDGEMENTS}

We thank G. Brosi from the Fish and Game Department of canton Grisons for kindly providing the mortality data. We also acknowledge the efforts of numerous game wardens who actually recorded the data. Part of the meteorological data used in this study was provided by the Swiss Federal Office of Meteorology and Climatology. We thank M. Zappa for helping with WinMet, and E. Greene, M. Garel and an anonymous reviewer for helpful comments. 


\section{REFERENCES}

Akaike, H. 1981. Likelihood of a model and information criteria. J. Economet., 16(1), 3-14.

Anderton, S.P., S.M. White and B. Alvera. 2004. Evaluation of spatial variability in snow water equivalent for a high mountain catchment. Hydrol. Process., 18(3), 435-453.

Boyce, M.S. and 6 others. 2003. Scale and heterogeneity in habitat selection by elk in Yellowstone National Park. Ecoscience, 10(4), 421-431.

Cederlund, G.N., H.K.G. Sand and A. Pehrson. 1991. Body mass dynamics of moose calves in relation to winter severity. J. Wildlife Manage., 55(4), 675-681.

Crampe, J.P., J.C. Caens, J.L. Dumerc and D. Pepin. 1997. La masse corporelle comme indicateur de la condition physique hivernale de I'Isard Rupicapra pyrenaica (Artiodacyla, Bovidae). Mammalia, 61(1), 73-85.

Dailey, T.V. and N.T. Hobbs. 1989. Travel in alpine terrain: energy expenditures for locomotion by mountain goats and bighorn sheep. Can. J. Zool., 67(10), 2368-2375.

Foppa, N., A. Stoffel and R. Meister. 2007. Synergy of in situ and space borne observation for snow depth mapping in the Swiss Alps. Int. J. Appl. Earth Obs. Geoinform., 9(3), 294-310.

Gaillard, J.-M., D. Delorme, J.-M. Boutin, G. van Laere, B. Boisaubert and R. Pradel. 1993. Roe deer survival patterns: a comparative analysis of contrasting populations. J. Animal Ecol., 62(4), 778-791.

Giacometti, M. and 6 others. 2002. Mycoplasma conjunctivae infection is not maintained in alpine chamois in eastern Switzerland. J. Wildlife Diseases, 38(2), 297-304.

Gonzales, G. and J.-P. Crampe. 2001. Mortality patterns in a protected population of isards (Rupicapra pyrenaica). Can. J. Zool., 79(11), 2072-2079.

Gyalistras, D. 2003. Development and validation of a highresolution monthly gridded temperature and precipitation data set for Switzerland (1951-2000). Climate Res., 25(1), 55-83.

Haberlandt, U. 2007. Geostatistical interpolation of hourly precipitation from rain gauges and radar for a large-scale extreme rainfall event. J. Hydrol., 332(1-2), 144-157.

Hovey, F.W. and A.S. Harestad. 1992. Estimating effects of snow on shrub availability for black-tailed deer in southwestern British Columbia. Wildlife Soc. Bull., 20(3), 308-313.

Johnson, C.J., K.L. Parker, D.C. Heard and M.P. Gilingham. 2002.
Movement parameters of ungulates and scale-specific responses to the environment. J. Animal Ecol., 71(2), 225-235.

Leuthold, H., B. Allgöwer and R. Meister. 1997. Visualization and analysis of the Swiss Avalanche Bulletin using GPS. In ISSW' 96. International Snow Science Workshop, 6-10 October 1996, Banff, Alberta, Canada. Proceedings. Revelstoke, BC, Canadian Avalanche Association, 35-42.

Loison, A. and R. Langvatn. 1998. Short- and long-term effects of winter and spring weather on growth and survival of red deer in Norway. Oecologia, 116(4), 489-500.

Loison, A., J.-M. Jullien and P. Menaut. 1999. Relationship between chamois and isard survival and variation in global and local climate regimes: contrasting examples from the Alps and Pyrenees. In Hofgaard, A., J.P. Ball, K. Danell and T.V. Callaghan, eds. Animal responses to global change in the North. Oxford, Blackwell Publishing, 126-136. (Ecological Bulletins 47.)

Michallet, J., J.-M. Gaillard, C. Toïgo and N.G. Yoccoz. 1999. Winter quarter selection by Chamois, Rupicapra rupicapra, in the mountain massifs of Isre (France). Rev. Ecol. Terre Vie, 54(4), 351-363.

Parker, K.L., C.T. Robbins and T.A. Hanley. 1984. Energy expenditures for locomotion by mule deer and elk. J. Wildlife Manage., 48(2), 474-488.

Putkonen, J. and G. Roe. 2003. Rain-on-snow events impact soil temperatures and affect ungulate survival. Geophys. Res. Lett., 30(4), 1188. (10.1029/2002GL016326.)

Rose, K.E., T.H. Clutton-Brock and F.E. Guinness. 1998. Cohort variation in male survival and lifetime breeding success in red deer. J. Animal Ecol., 67(6), 979-986.

Solberg, E.J. and 6 others. 2001. Effects of density-dependence and climate on the dynamics of a Svalbard reindeer population. Ecography, 24(4), 441-451.

Verme, L.J. 1968. An index of winter weather severity for northern deer. J. Wildlife Manage., 32(3), 566-574.

Visscher, D.R., E.H. Merrill, D. Fortin and J.L. Frair. 2006. Estimating woody browse availability for ungulates at increasing snow depths. Forest Ecol. Manage., 222(1-3), 348-354.

Viviroli, D., J. Gurtz and M. Zappa. 2007. The hydrological modelling system PREVAH. Model documentation and user model. Geogr. Bern. P40.

Wiersema, G. 1989. Climate and vegetation characteristics of Ibex habitats in the European Alps. Mt. Res. Dev., 9(2), 119-128.

$\mathrm{Xu}$, R. 2003. Measuring explained variation in linear mixed effects models. Stat. Med., 22(22), 3527-3541. 